\title{
INTERAKTIVITAS DAN LEARNER CONTROL PADA MULTIMEDIA INTERAKTIF
}

\section{Abstrak}

Mulitmedia Interaktif adalah suatu medium yang menyediakan interaktivitas yang lebih luas bila dibandingkan dengan media lain. Salah satu bentuk dari interaktivitas yang disediakan oleh multimedia adalah learner control. Learner control adalah suatu kontrol yang memberikan keleluasaan bagi pengguna untuk menjelajahi isi dari multimedia. Ada 3 jenis learner control: content control, pace control, and display control.

Adanya learner control memberikan suatu nilai tambah di dalam multimedia yakni memberikan pilihan bagi pengguna (personalize) sesuai dengan selera dan kemampuannya. Di dalam suatu multimedia, dengan adanya GUI (Graphical User Interface), mungkin saja suatu learner control telah tersedia secara inheren; tetapi akan lebih bermanfaat bagi pengguna bila learner control ini dirancang sejak awal sehingga learner control ini menyatu dengan materi yang diberikan.

Tulisan ini mencoba membedah sedikit interaktivitas pada umumnya dan learner control pada khususnya serta mengkaji bagaimana penerapan learner control dalam suatu multimedia pembelajaran interaktif.

Kata Kunci: interaktivitas, content control, pace control, display control, GUI.

\section{PENGANTAR}

Tulisan ini akan membahas masalah interaktivitas dalam multimedia interaktif. Salah satu bentuk interaktivitas adalah learner control. Learner control umumnya berupa suatu content control, pace control atau

*) Drs. Gatot Pramono, M.Pet., adalah Staf pada Studio Multimedia Pustekkom Depdiknas 
display control. Keberadaan learner control dalam suatu medium seperti multimedia bisa saja muncul tanpa suatu desain yang terencana karena multimedia, baik dalam skala kecil atau besar, pasti memanfaatkan graphical user interface (GUI). Tetapi suatu learner control yang didesain secara apik melalui pengaturan menu yang sesuai dengan prinsip pemanfaatan GUI dan pengaturan yang sesuai dengan prinsip suatu desain instruksional tentulah memberikan manfaat yang lebih bagi pengguna yang akan mempelajari materi pembelajaran.

Learner control sangat erat hubungannya dengan interaktivitas. Oleh karena itu, sebelum uraian mengenai learner control, uraian tentang interaktivitas akan diberikan terlebih dahulu. Bagain terakhir dari tulisan ini akan menguraikan contoh-contoh learner control dalam suatu program multimedia yang berisi tutorial dan simulasi suatu oscilloscope.

\section{MULTIMEDIA DAN INTERAKTIVITAS}

Komputer sebagai medium pembelajaran merupakan medium yang belakangan muncul dibandingkan media lain. Kehadirannya yang sarat teknologi disamping menjanjikan banyak keunggulan juga perangkap bagi para technophylia yang secara simplisitis melihat masalahmasalah pembelajaran dapat diselesaikan dengan kehadiran komputer.

Salah satu keunggulan komputer dibandingkan dengan media yang lain adalah kemampuannya dalam menghadirkan suatu tiruan (model) dari suatu fenomena, peralatan, lab, atau percobaan. Tiruan atau model ini penting manakala kita ingin memberikan pembelajaran yang menyangkut sesuatu yang baik dari segi biaya, keamanan atau kendala-kendala lain yang sulit dihadirkan secara nyata. Sebagai contoh: menghadirkan suatu rapat reaksi berantai dalam reaktor nuklir di depan siswa tentulah hal yang mustahil; demikian pula menghadirkan peristiwa alam seperti tsunami. Dengan komputer orang dapat mempelajari hal-hal yang sulit dihadirkan tersebut dengan lebih murah dan aman. Dengan pemrograman yang canggih bahkan kondisi tiruan 
dapat dihadirkan mendekati keadaan yang sesungguhnya, misal dalam simulasi menerbangkan helikopter atau pesawat terbang.

Keunggulan yang lain adalah interaktivitas. Komputer memiliki suatu perangkat lunak yang telah diprogram sebelumnya (pre-programmed) di mana berbagai kemungkinan telah diperhitungkan dan disiapkan sebelumnya. Pemrograman yang canggih akan memungkinkan pengguna menikmati interaktivitas yang lebih luas bila dibandingkan menggunakan media yang lain. Interaktivitas di sini selain percobaan atau simulasi dari suatu model seperti yang dijelaskan pada paragraf sebelumnya juga meliputi: kebebasan dalam pemilihan materi, kebebasan dalam memilih tampilan, dan kebebasan dalam memilih variabel-variabel yang lain misal warna dari tampilan, jenis dan ukuran huruf (font) dan kebebasan dalam mengganti tampilan lain (GUI Graphical User Interface).

Kemampuan komputer dalam pemrograman ini bahkan menjanjikan suatu keunggulan lain yang lebih tinggi levelnya dibandingkan interaktivitas-interaktivitas yang telah disebutkan. Keunggulan yang menjanjikan ini adalah apa yang disebut kecerdasan buatan atau artificial intelligent (Al) dan expert system. Dengan Al atau expert system, komputer bukan lagi perangkat bodoh (bodoh di sini dalam arti hanya bereaksi terhadap sesuatu yang telah diprogram sebelumnya) tetapi telah meningkat menjadi perangkat pintar (smart). Komputer pintar, dengan kecerdasan buatannya, mampu memberikan solusi dan jawaban dengan berbagai kemungkinan yang jauh lebih luas dibandingkan komputer bodoh. Komputer pintar dapat menyediakan dialog yang cerdas antara pengguna dan komputer.

Komputer akan mampu menjawab berbagai kemungkinan input dari pengguna. Dengan adanya dialog (merupakan salah satu aspek penting dalam constructivism) (Garrison, 1993), kita dapat memasukkan pendekatan constructivism dalam pembelajaran yang dikemas dalam komputer yang memiliki Al atau expert system . Sayangnya sampai hari ini kemampuan dari komputer pintar semacam itu belum lagi 
terwujud. Sekalipun Al dan expert system terus berkembang tetapi kemampuannya dalam memberikan dialog yang luas belum memberikan hasil yang memuaskan. Hal inilah yang oleh Bates (1995) disebut sebagai broken promises dari teknologi komputer. Bates menjelaskan: " It has proved remarkably difficult to model real teacher behaviour in a convincing way on a computer".

\section{INTERAKSI DAN LEARNER'S CONTROL \\ - Interaksi}

Teknologi senantiasa menyediakan antar muka (interface) yang menghubungkan pengguna dengan teknologi itu sendiri atau menghubungkan pengguna dengan pengguna yang lain. Hubungan antara pengguna-teknologi atau pengguna-pengguna berbentuk komunikasi real-time (synchronous) atau komunikasi asynchronous, komunikasi dua-arah atau komunikasi satu-arah, komunikasi permanen atau komunikasi sesaat (transien ). Adanya komunikasi-komunikasi di atas memungkinkan terjadinya interaksi dan kemudahan dalam pemanfaatan teknologi (user-friendliness) (Bates, 1995).

Dilihat dari bagaimana pengguna bereaksi terhadap suatu medium, interaksi dibedakan antara interaksi yang terbuka (overt) dan tertutup (covert). Contoh interaksi yang terbuka adalah simulasi di mana setelah pengguna menggerakkan mouse, menekan tombol atau memasukkan nilai dari variabel-variabel tertentu ia akan melihat perubahan yang terjadi. Contoh interaksi yang tertutup adalah saat pengguna berusaha menyerap materi yang disajikan dengan kemampuan kognitifnya tanpa melakukan suatu aksi motorik seperti menekan tombol atau menggerakkan mouse.

Interaksi memiliki 2 fungsi (Steinberg, 1991), yang pertama adalah fungsi mekanis: interaksi menyediakan fasilitas-fasilitas yang menghubungkan pengguna dengan program, baik melalui penekanan tombol, klik atau pergerakan mouse, pergerakan track ball, pergerakan joystick, maupun sentuhan pada layar sentuh (touch screen). Dengan fungsi mekanis ini pengguna dapat 
memasukkan, menghapus atau mengubah nilai variabel-variabel tertentu, memilih menu, mengganti tampilan , dll. Fungsi yang kedua adalah membantu pembelajaran. Contoh dari fungsi yang kedua inilah adalah interaksi dalam bentuk tes atau pertanyaan yang kemudian setelah pengguna menjawab maka program mengeluarkan respon atau umpan balik (feedback).

Interaksi adalah suatu fitur yang menonjol dalam multimedia yang memungkinkan pembelajaran yang aktif (active learning). Pembelajaran yang aktif tidak saja memungkinkan siswa (pengguna) melihat atau mendengar (see and hear) tetapi juga melakukan sesuatu (do). Dalam konteks multimedia do disini dapat berupa: memberikan respon terhadap pertanyaan yang diajukan komputer atau aktif dalam simulasi yang disediakan komputer. Fenrich (1997) menjelaskan beberapa cara untuk mengimplementasikan interaksi pada multimedi, yaitu:

- Memancing pengguna untuk menjawab pertanyaan yang memerlukan pemikiran.

- Melibatkan pengguna dalam simulasi atau game yang bersifat edukatif.

- Memberikan umpan balik terhadap masukan (jawaban) dari pengguna.

- Memberikan materi yang sesuai dengan pengetahuan yang dimiliki oleh pengguna.

- Memberikan keleluasaan bagi pengguna untuk menentukan (mengontrol) kecepatan (pacing) yang sesuai dengan kemampuan mereka dalam menjelajahi materi.

- Memancing pengguna untuk memberikan komentar dan catatan.

- Memberikan cara yang fleksibel bagi pengguna untuk mengubah tampilan dari program.

Menurut hemat penulis point terakhir dari saran Fenrich di atas adalah keleluasaan dalam mengubah tampilan graphical user interface (GUI) dari program. 
Multimedia sebagai medium yang berbasis komputer tentu saja menyediakan komunikasi-komunikasi seperti yang disebutkan di atas sekalipun tidak semua komunikasi yang ada tersedia. Komunikasi inilah yang memunculkan interaksi. Bahkan interaksi sendiri merupakan suatu fitur yang menonjol pada multimedia; nilai lebih dari multimedia ditentukan dari seberapa luas dan bermakna interaksi yang disediakan oleh suatu paket multimedia. Suatu multimedia yang menyediakan suatu interaksi yang hanya memungkinkan pengguna menekan tombol untuk mengganti tampilan, sebagaimana jari tangan digunakan untuk membalik halaman buku, tentulah bukan multimedia yang ideal.

Suatu terminologi lain yang sering dihubungkan dengan interaksi adalah learner's control. Kedua istilah ini mungkin memiliki arti yang tumpang tindih, tapi jelas keduanya memiliki penekanan yang berbeda. Suatu learner control tentu saja berarti suatu interaksi, tetapi suatu interaksi belum tentu mengandung suatu learner control. Interaksi memiliki spektrum yang luas dari sekedar yang bersifat sederhana (trivial) sampai yang kompleks seperti mengendalikan joystick atau interaksi yang merangsang kemampuan kognitif di dalam otak seperi pada interaksi yang bersifat covert. Interaksi tidak selalu bermakna pembelajaran (learning).

Sementara itu, learner control selalu berkaitan erat dengan proses pembelajaran (learning). Merill (1994) menjabarkan beberapa tipe learner control diantaranya adalah: content control, control of pace, dan display control. Content control adalah learner control yang memungkinkan pengguna untuk memilih sendiri konten atau materi yang sesuai dengan kebutuhannya. Control of pace adalah learner control yang memungkinkan pengguna untuk memilih kecepatan dalam memahami materi sesuai dengan kemampuannya. Display control adalah learner control yang memberikan kebebasan pada pengguna untuk menentukan sendiri tipe, jenis atau jumlah display yang ia inginkan dan sesuai dengan kebutuhannya. Adanya learner control inilah yang menjadikan suatu medium bersifat individualized 
instruction. Ini berarti tampilan, isi, susunan atau urutan dari materi yang disuguhkan oleh suatu medium pembelajaran tampak berbeda-beda di depan pengguna yang satu dan pengguna yang lainnya.

Merill (1997) menjelaskan bahwa suatu pembelajaran bernilai instruksional bila terdapat 3 hal penting: presentation, practice, dan learner guidance. Presentation bermakna presentasi dari materi pembelajaran. Practice bermakna latihan di mana dalam hal ini pengguna mencoba skill atau keahlian yang diberikan di dalam instruksional. Learner guidance bermakna panduan (pertolongan) dalam menggunakan paket instruksional. Learner guidance ini di dalam multimedia tidak bermakna sempit sebagai petunjuk penggunaan tetapi lebih luas lagi dari hal itu. Gambar, tabel, keterangan atau apa saja yang membantu pengguna dalam memahami materi disebut learner guidance. Sebagai contoh dalam materi tentang lensa gambar sinar beserta arahnya adalah suatu learner guidance.

\section{CONTOH IMPLEMENTASI INTERAKSI DAN LEARNER CONTROL PADA MULTIMEDIA}

Sekarang kita lihat contoh implementasi interaksi dan learner control pada suatu program MMI. Program yang kita bahas di sini adalah suatu program simulasi dari suatu oscilloscope. Perangkat oscilloscope adalah suatu perangkat elektronik yang sangat bermanfaat dalam mengukur serta melihat bentuk-bentuk gelombang suatu sinyal elektronik. Dengan oscilloscope kita tidak hanya dapat mengukur besarnya tegangan suatu sinyal elektronik, tetapi lebih jauh lagi dapat mengukur frekuensi, melihat bentuk gelombang suatu sinyal elektronik, dan bahkan mengukur beda fase antara dua buah sinyal elektronik.

Oscilloscope merupakan suatu peralatan yang harganya relatif mahal. Sementara kemampuan yang diperlukan dalam menggunakannya adalah membaca (mengukur) sinyal yang nampak pada layar. Kemampuan membaca sinyal oscilloscope tentulah bukan suatu 
keahlian yang sulit, bahkan relatif mudah diperoleh. Sekalipun demikian bagi pemula memperoleh kemampuan membaca sinyal elektronik pada oscilloscope cukup memakan waktu. Sementara penggunaan yang ceroboh dari para pemula akan mengakibatkan peralatan mahal ini rusak. Atas pertimbangan-pertimbangan inilah tim pengembang MM dari Pustekkom Depdiknas mengembangkan suatu model simulasi dari suatu oscilloscope. Harapan tim pengembang adalah: para pemula yang ingin belajar membaca dan mengukur sinyal elektronik pada oscilloscope dapat menggunakan simulasi ini tanpa harus menggunakan peralatan asli yang berisiko merusakkannya. Jadi tujuan utama dari pembuatan simulasi oscilloscope ini adalah membantu para pemula (terutama para siswa sekolah kejuruan) dalam membaca dan mengukur sinyal elektronik pada oscilloscope.

Dalam simulasi oscilloscope ini tentu saja tidak semua kondisi aslinya ditampilkan. Fitur-fitur utama yang ditampilkan meliputi: pengatur tegangan ( Volt/Div), pengatur frekuensi ( Time/Div), pemilih channel, tombol Add (untuk menjumlahkan dua buah sinyal), tombol Dual (untuk menampilkan dua buah sinyal secara bersamaan pada layar) serta tombol X-Y (untuk melihat gambar Lissajous yang berguna dalam mengukur beda fase antara dua buah sinyal listrik). Program simulasi oscilloscope saat ini memiliki versi 0.1 ; kemungkinan untuk mengembangkan versi lebih lanjut dengan penambahan fitur tentu saja masih terbuka kemungkinannya sepanjang program ini kelak ternyata bermanfaat bagi para pengguna (khususnya siswa sekolah kejuruan).

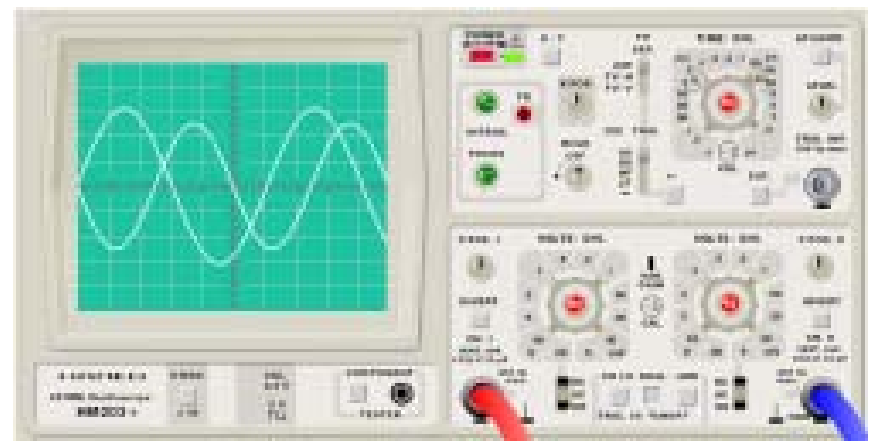

Gambar 1. Tampilan dari program simulasi oscilloscope 
- Content control pada program oscilloscope Content control pada oscilloscope memanfaatkan graphical user interface (GUI). Toolbar (gambar 2) digunakan untuk menempatkan menu-menu yang ada. Toolbar senantiasa tampak (visible) pada tiap halaman (display) dari program ini, hal ini dimaksudkan untuk memudahkan pengguna dalam mengakses menu-menu yang ada. Analogi dari menu-menu pada toolbar adalah daftar isi pada buku. Keunggulan dari menu pada toolbar dibandingkan daftar isi pada buku adalah akses yang lebih cepat. Bila pada buku pembaca harus kembali ke daftar isi kemudian mencari halaman yang diinginkan, maka dengan menu pada toolbar pengguna cukup menggerakkan mouse untuk mengakses halaman-halaman yang diinginkan. Bahkan pada penggunaan GUI yang baik, menu-menu semestinya disertai tombol-tombol kunci tertentu (misal menu File disertai kombinasi tombol $A L T+F$ ) sehingga untuk mengaksesnya diperlukan waktu yang cepat.

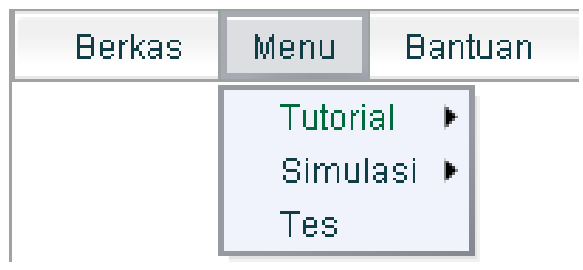

Gambar 2. Tampilan menu dari program oscilloscope

Perlu digaris-bawahi di sini bahwa menu-menu yang ada tidak selalu terkait dengan materi pembelajaran, hal-hal lain di luar materi pembelajaran juga disertakan di dalam menu. Sebagai contoh menu Berkas berisi submenu Kompetensi, Cetak dan Keluar. Bila Kompetensi diaktifkan maka kompetensi yang didapatkan setelah pengguna menggunakan program ini akan ditampilkan pada layar. Bila Cetak diaktifkan maka gambar oscilloscope akan dicetak ke printer. Keluar digunakan untuk keluar dari program.

Menu Bantuan berisi submenu: Cara Menggunakan Program, Daftar Istilah, Kalkulator dan Tentang Program. Bila Cara 
Menggunakan Program diaktifkan maka petunjuk cara menggunakan program oscilloscope akan ditampilkan. Bila Daftar Istilah diaktifkan maka seluruh istilah-istilah yang digunakan dalam program ini akan ditampilkan. Kalkulator berguna manakala pengguna merasa perlu untuk menghitung amplitudo atau frekuensi dari sinyal. Dan Tentang Program menampilkan informasi tentang versi dari program serta tim pengembangnya.

Menu yang berkaitan dengan materi pembelajaran dikumpulkan di dalam Menu. Menu ini memiliki sub menu : Tutorial, Simulasi dan Tes. Submenu Tutorial memiliki sub-submenu : Fungsi Tombol, Kalibrasi dan Pembacaan (gambar 3). Submenu Simulasi memiliki sub-submenu: Fungsi Tombol Generator Fungsi, Simulasi Terbatas, dan Simulasi dengan Generator Fungsi (Gambar 4).

Submenu Fungsi Tombol bermanfaat bagi pengguna yang ingin mengenal nama-nama dan fungsi dari tombol atau knob yang dimiliki oleh suatu oscilloscope. Submenu Kalibrasi untuk saat ini belum diaktifkan. Submenu Pembacaan bermanfaat bagi pengguna yang ingin belajar cara-cara membaca amplitudo, frekuensi atau beda fase sinyal elektronik.

Dengan bantuan dari menu-menu pada toolbar dan sub-submenu yang menyertainya pengguna dapat dengan mudah memilih menu (dan sub-submenunya) yang dikehendaki dan yang sesuai dengan kemampuannya saat itu. Toolbar beserta menu-menunya tersebut senantiasa tampak pada bagian atas dari window, tak soal ada di bagian mana pengguna sedang mengakses konten dari program. Toolbar yang selalu visible ini tentu saja memudahkan pengguna untuk berpindah-pindah menu. Hal ini memang merupakan suatu implementasi dari GUI (Pramono, 2005). Dengan susunan menu seperti ini mudah bagi pengguna untuk berpindah dari satu konten ke konten lainnya. Sebagai contoh seorang pengguna tengah mencoba menu Pembacaan Frekuensi dan ternyata ia lupa bagaimana cara kerja tombol Time/Div yang berguna untuk mengatur frekuensi. Untuk melihat cara kerja tombol Time/Div ia 
dengan mudah dan cepat berpindah ke menu Fungsi Tombol untuk mempelajari lagi cara kerja Time IDiv.

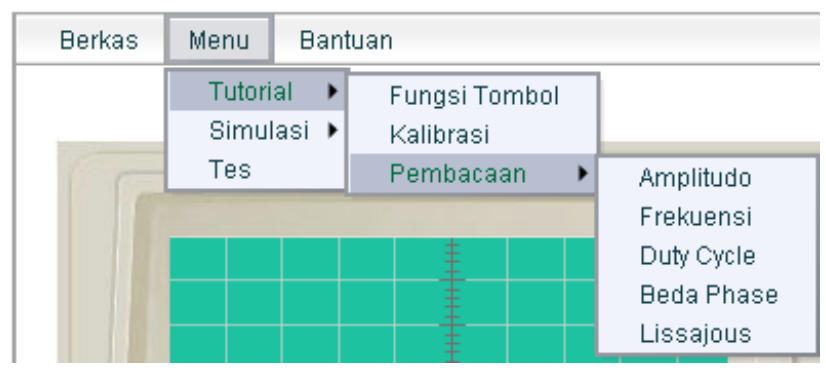

Gambar 3. Tampilan submenu Tutorial dengan sub-submenunya

\begin{tabular}{|c|c|c|c|}
\hline \multirow[t]{5}{*}{ Berkas } & Menu & \multicolumn{2}{|c|}{ Bantuan } \\
\hline & \multicolumn{2}{|c|}{ Tutorial } & \\
\hline & \multicolumn{2}{|c|}{ Simulasi } & Fungsi Tombol Generator Fungsi \\
\hline & \multicolumn{2}{|l|}{ Tes } & Simulasi Terbatas \\
\hline & & & Simulasi dengan Generator Fungsi \\
\hline
\end{tabular}

Gambar 4. Tampilan submenu Simulasi dengan sub-submenunya

Selain penggunaan menu pada toolbar, komponen GUI lain yang digunakan adalah suatu combo-box yang berfungsi untuk memilih jenis tombol yang ingin diperlihatkan (gambar 5).

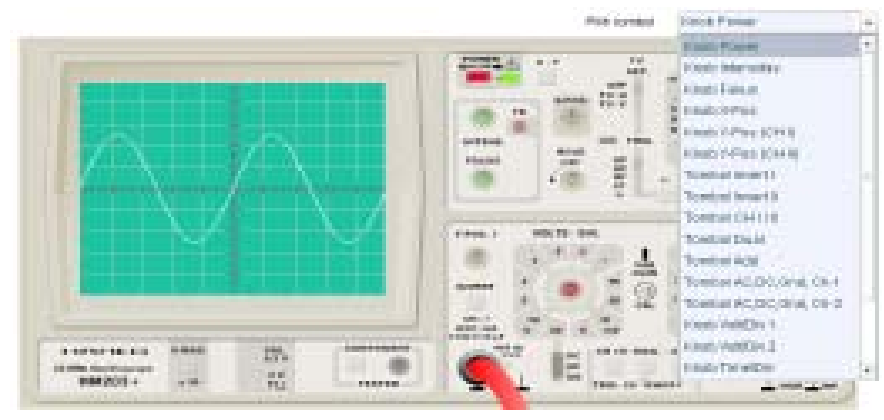

Gambar 5. Combo Box yang berfungsi untuk memilih jenis tombol yang digunakan 
Tombol combo box ini sengaja diletakkan terpisah dari menu mengingat banyaknya pilihan yang ada, di samping itu pilihanpilihan dari combo box merupakan sub-submenu khas dari submenu Fungsi Tombol.

Pemanfaatan toolbar dan combo box di atas merupakan implementasi dari content control pada program oscilloscope. Yang perlu digaris-bawahi di sini adalah bagaimana suatu program multimedia mampu mengimplementasikan suatu content control dengan mudah melalui pemanfaatan GUI.

- Control of Pace pada program oscilloscope Implementasi dari control of pace pada program oscilloscope ini memang tidak terlalu kuat. Program oscilloscope ini sejatinya memang bukan suatu individualized instruction di mana tiap pengguna akan menemukan tampilan atau tingkat kesulitan yang berbeda. Di sini, pengguna akan menemukan suatu tampilan dan tingkat kesulitan yang sama. Program memang tidak dipilah untuk pengguna tingkat pemula, menengah, atau mahir. Kalaupun ada semacam control of pace yang tipis, hal itu nampak pada pemilihan jenis simulasi (lihat gambar 5.) yaitu simulasi yang terbatas (diimplementasikan dalam submenu Simulasi Terbatas) dan simulasi bebas (diimplementasikan dalam submenu Simulasi Dengan Generator Fungsi).

Simulasi Terbatas adalah simulasi dengan sinyal input yang memiliki nilai amplitudo dan frekuensi yang tetap. Pengguna hanya melihat perubahan besar amplitudo dan frekuensi pada layar dengan mengatur Volt/Div dan Time/Div. Pengaturan Volt/Div dan Time/Div sama sekali tidak mengubah nilai amplitudo atau frekuensi sinyal, tapi hanya mengatur skala tampilan pada layar. Simulasi Terbatas ini ditujukan bagi pengguna pemula yang ingin mencoba dan mengaplikasikan tombol-tombol yang paling penting yaitu tombol Volt/Div dan Time/Div. 
Simulasi Dengan Generator Fungsi adalah simulasi dengan sinyal yang berasal dari suatu generator sinyal. Di sini ada 2 generator sinyal yang nilai amplitudo dan frekuensinya dapat diatur sesuai dengan keinginan pengguna. Bahkan perbedaan fase dari sinyal-sinyal yang keluar dari keduanya dapat diatur juga. Simulasi Dengan Generator Fungsi ini ditujukan untuk pengguna mahir yang sudah tahu cara mengoperasikan tombol-tombol Volt/Div dan Time/Div dan yang ingin mencoba tombol-tombol lain pada oscilloscope semisal tombol $\mathbf{X}-\mathbf{Y}$ yang berguna untuk melihat perbedaan fase antara kedua sinyal input. Dengan mengatur beda fase dan beda frekuensi antara kedua sinyal pengguna dapat melihat gambar Lissajous yang menunjukkan perbedaan fase dan frekuensi pada kedua sinyal input (lihat gambar 6).

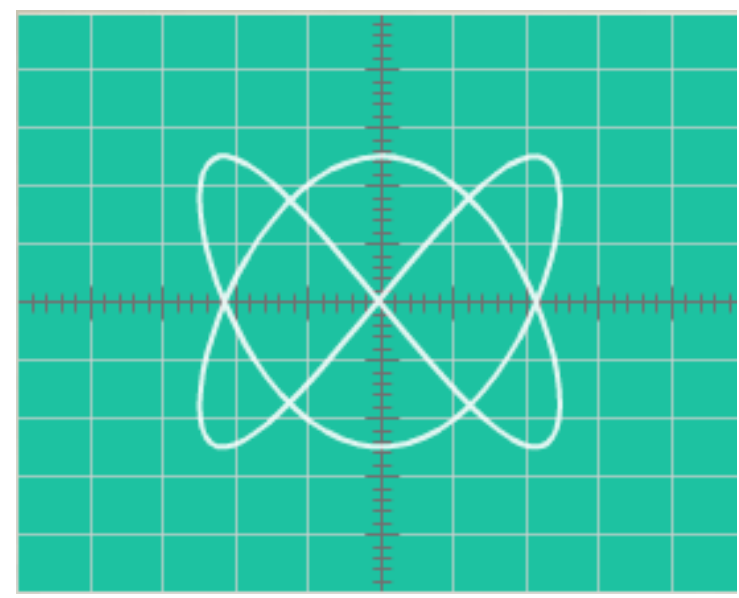

Gambar 6. Contoh gambar Lissajous yang ditampilkan oleh program Oscilloscope.

- Display Control pada program oscilloscope

Simulasi oscilloscope secara inheren telah memuat display control. Tombol Volt/Div, Time/Div, CH I/II, Dual atau Add semuanya berfungsi untuk memfasilitasi display control. Tombol Volt/Div berfungsi untuk mengubah nilai unit dari tegangan (dalam satuan volt). Nilai Volt/Div pada posisi 1 berarti tiap satu satuan grid bernilai 
1 volt, bila Volt/ Div pada posisi 2 berarti tiap satu satuan grid bernilai 2 volt. Gambar-gambar di bawah ini menunjukkan tampilan display yang berbeda ketika nilai Volt/Div berbeda.

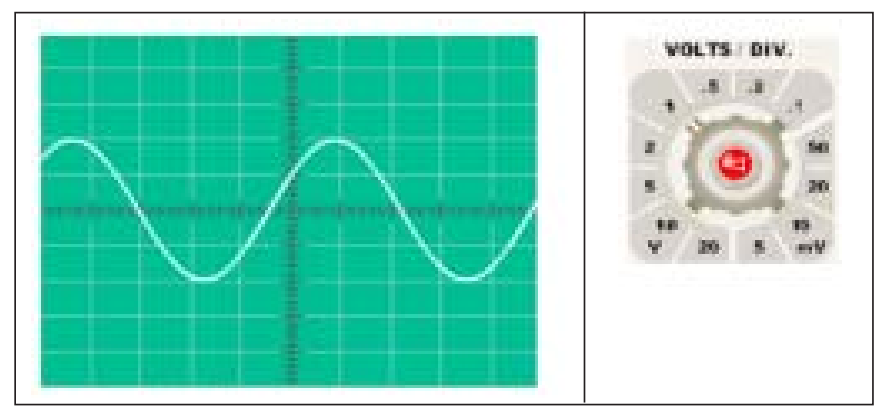

Tampilan display oscilloscope untuk Volt/Div pada posisi 1; di sini nilai tegangan bernilai 4 volt

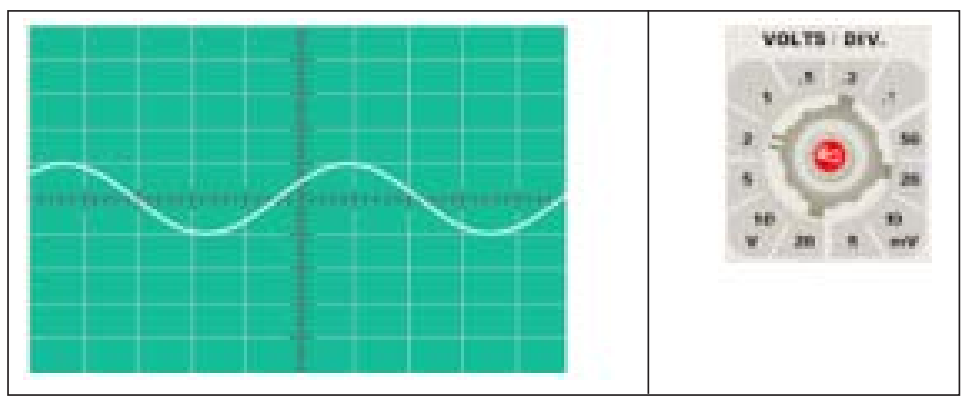

Tampilan display oscilloscope untuk Volt / Div pada posisi 2; di sini nilai tegangan tetap bernilai 4 volt

Program oscilloscope menyediakan 2 buah generator yang keduanya dapat dimasukkan secara bersamaan pada 2 channel yang berbeda. Dengan bantuan mouse, kedua generator dapat ditampilkan secara bergantian pada layar. 

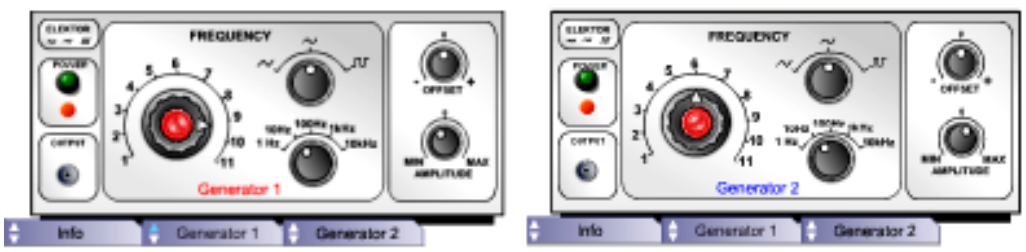

Generator 1 dan 2 dapat ditampilkan secara bergantian dengan memanfaatkan tabbing panel di bagian bawah.

Dengan mengaktifkan kedua generator pengguna dapat mengatur besarnya tegangan maupun frekuensi yang diinginkan. Lebih jauh lagi pengguna dapat memilih jenis gelombang: gelombang sinus, gelombang gigi gergaji atau gelombang kotak.

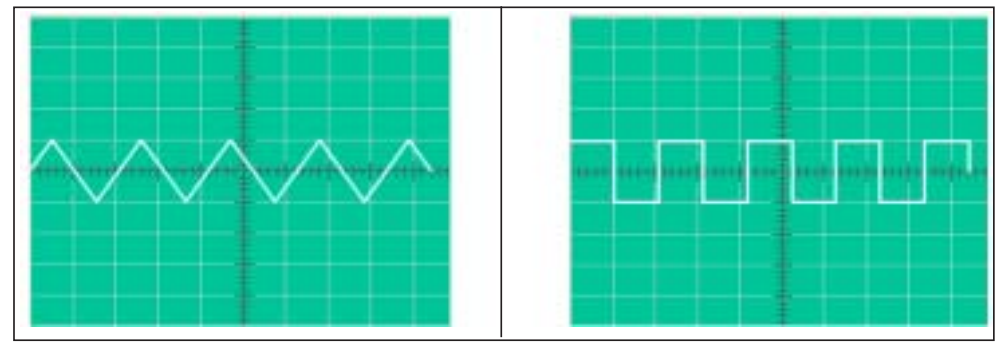

Sinyal berbentuk gigi gergaji dan sinyal berbentuk kotak pada display

Dengan seluruh fasilitas yang ada pada program oscilloscope, pengguna dapat mencoba seluruh tampilan yang ada, baik dengan memanfaatkan tombol-tombol yang tersedia pada oscilloscope maupun dengan memanfaatkan tombol-tombol pada kedua generator. Pengguna selain dapat menampilkan keluaran (output) dari kedua generator secara bergantian, juga dapat menampilkan keduanya secara bersamaan, menjumlahkan kedua gelombang, bahkan menampilkan dalam bentuk gambar Lissajous untuk melihat perbedaan fase di antara keduanya. Keleluasaan semacam ini memungkinkan pengguna untuk mencoba secara maksimal semua tampilan yang disediakan oleh program. 


\section{PENUTUP}

Dengan memilih materi pembelajaran yang tepat, suatu program Multimedia interaktif dapat digunakan untuk melakukan simulasi atau tiruan dari suatu fenomena bahkan suatu peralatan yang nyata. Program oscilloscope yang ditunjukkan di atas merupakan suatu contoh nyata bagaimana komputer dapat digunakan untuk menirukan suatu alat penting. Simulasi selain sebagai alat bantu dalam pembelajaran juga bermanfaat sebagai pengganti dari suatu keadaan atau alat yang riel manakala keadaan atau alat yang riel terlalu sulit atau terlalu mahal bila dihadirkan dihadapan para siswa atau pengguna.

MM interaktif memberikan keleluasaan bagi suatu materi pembelajaran yang dirancang dapat menyediakan suatu content control, pace control dan display control. Sekalipun learner control semacam ini belum mendapatkan perhatian yang luas dalam studi atau riset untuk melihat pengaruhnya dalam pembelajaran (Merill, 1994), keberadaannya dalam suatu program multimedia menjadikan materi pembelajaran lebih luas, hidup dan menyenangkan bagi penggunanya dibandingkan bila diberikan dengan media yang lain. Nilai utama dari suatu simulasi tentu saja adalah keadaan dan pengalaman yang dirasakan oleh pengguna yang mendekati keadaan dan pengalaman yang sesungguhnya.

\section{REFERENSI}

Bates, A.W. (1995) Technology, Open Learning and Distance Education, London : Routledge.

Fenrich, P. (1997) Practical Guidelines for Creating Instructional Multimedia Applications, Forth Worth : The Dryden Press.

Garrison, D.R. (1993) A cognitive constructivist view of distance education: An analysis of teaching-learning assumption, Distance Education, 14,2, 199-211.

Merill, M.D (1994) What is Learner Control, dalam Twitchell D. G.(Ed). Instructional Design Theory.

Merill, M.D (1997) Instructional Strategies that Teach, CBT Solutions, 
Nov./Dec. 1997 1-11.

Philips, R. (1997) The Developer's Handbook To Interactive Multimedia: A Practical Guide for Educational Applications, London: Kogan Page.

Pramono, G. (2005) Graphical User Interface (GUI) Dan Pemanfaatannya Dalam Perangkat Lunak, Jurnal Teknodik, Tahun ke - IX, No.17, 2005.

Steinberg, E. S (1991) Computer-Assisted Instruction : A Synthesis Of Theory, Practice, And Technology, New Jersey: Lawrence Erlbaum Associates. 